\title{
Low socioeconomic status and severe obesity are linked to poor cognitive performance in Malaysian children
}

Bee Koon Poh ${ }^{1 *}$, Shoo Thien Lee ${ }^{1}$, Giin Shang Yeo ${ }^{1}$, Kean Choon Tang ${ }^{1}$, Ab. Rahim Noor Afifah ${ }^{1}$, Awal Siti Hanisa ${ }^{1}$, Panam Parikh², Jyh Eiin Wong ${ }^{1}$, Alvin Lai Oon $\mathrm{Ng}^{3}$ and on behalf of the SEANUTS Study Group

\begin{abstract}
Background: Socioeconomic factors and nutritional status have been associated with childhood cognitive development. However, previous Malaysian studies had been conducted with small populations and had inconsistent results. Thus, this present study aims to determine the association between socioeconomic and nutritional status with cognitive performance in a nationally representative sample of Malaysian children.
\end{abstract}

Methods: A total of 2406 Malaysian children aged 5 to 12 years, who had participated in the South East Asian Nutrition Surveys (SEANUTS), were included in this study. Cognitive performance [non-verbal intelligence quotient (IQ)] was measured using Raven's Progressive Matrices, while socioeconomic characteristics were determined using parent-report questionnaires. Body mass index (BMI) was calculated using measured weight and height, while BMI-for-age Z-score (BAZ) and height-for-age Z-score (HAZ) were determined using WHO 2007 growth reference.

Results: Overall, about a third (35.0\%) of the children had above average non-verbal IQ (high average: 110119; superior: $\geq 120$ and above), while only $12.2 \%$ were categorized as having low/borderline IQ $(<80)$. Children with severe obesity (BAZ > 3SD), children from very low household income families and children whose parents had only up to primary level education had the highest prevalence of low/borderline non-verbal IQ, compared to their non-obese and higher socioeconomic counterparts. Parental lack of education was associated with low/borderline/below average IQ [paternal, $\mathrm{OR}=2.38(95 \% \mathrm{Cl} 1.22,4.62)$; maternal, $\mathrm{OR}=2.64(95 \% \mathrm{Cl} 1.32,5.30)$ ]. Children from the lowest income group were twice as likely to have low/borderline/below average IQ [OR $=2.01$ $(95 \% \mathrm{Cl} 1.16,3.49)]$. Children with severe obesity were twice as likely to have poor non-verbal IQ than children with normal BMI $[\mathrm{OR}=2.28(95 \% \mathrm{Cl} 1.23,4.24)]$.

Conclusions: Children from disadvantaged backgrounds (that is those from very low income families and those whose parents had primary education or lower) and children with severe obesity are more likely to have poor non-verbal IQ. Further studies to investigate the social and environmental factors linked to cognitive performance will provide deeper insights into the measures that can be taken to improve the cognitive performance of Malaysian children.

Keywords: Child, Cognition, Economic status, Intelligence, Obesity, Malaysia, Nutritional status

\footnotetext{
* Correspondence: pbkoon@ukm.edu.my

Bee Koon Poh is the National Co-ordinator, the SEANUTS Study Group

${ }^{1}$ Nutritional Sciences Programme \& Centre for Community Health, Faculty of Health Sciences, Universiti Kebangsaan Malaysia, Jalan Raja Muda Abdul Aziz, 50300 Kuala Lumpur, Malaysia

Full list of author information is available at the end of the article
}

(c) The Author(s). 2019 Open Access This article is distributed under the terms of the Creative Commons Attribution 4.0 International License (http://creativecommons.org/licenses/by/4.0/), which permits unrestricted use, distribution, and reproduction in any medium, provided you give appropriate credit to the original author(s) and the source, provide a link to the Creative Commons license, and indicate if changes were made. The Creative Commons Public Domain Dedication waiver (http://creativecommons.org/publicdomain/zero/1.0/) applies to the data made available in this article, unless otherwise stated. 


\section{Background}

Early childhood development has far reaching consequences on an individual's cognitive performance, which in turn affects his or her lifelong productivity, socioeconomic status (SES) and health. Cognitive performance involves the adaptive mental processes of perception, reasoning, creativity, problem solving and intuition that are measured by intelligence quotient (IQ) [1]. Poor cognitive development and low IQ levels among children may eventually lead to problems in mental health [2], social development, peer relationships as well as physical health [3], all of which can subsequently affect their quality of life when they are adults [4].

Poor cognitive performance in children has been linked with multiple risk factors related to low SES, such as parental education level and in particular low maternal schooling $[5,6]$, malnutrition, micronutrient deficiencies [7], non-stimulating environment [8], childhood infections [9, 10] and hearing impairment [11].

SES is a multidimensional construct typically characterized by education, income and occupation [12]. Results from developed and developing countries consistently supported the links among SES, nutritional status and cognitive performance [13-23]. Nutritional status, an associated factor of SES [13, 14], also plays a crucial rule in predicting cognitive performance. Good nutrition provides the building blocks for brain and neural system development [15]. Studies have regularly linked cognitive performance with both over- and under-nutrition. Sandjaja et al. [16] reported that both under- and over-nutrition can contribute to poor cognitive performance among Southeast Asian children aged 7-12 years. Another study has associated increased body mass index (BMI) with poor cognitive performance among children and adolescents aged 8 to 16 years in the United States [17]. An Indonesian study found that height-for-age Z-score (HAZ) of preschool children was positively associated with cognitive development [18]; while another study showed that stunted Indonesian children had slower development in fine and gross motor skills as well as poorer language skills, compared to non-stunted children [19]. Undernutrition in children is known to have long-term adverse effects on cognitive performance, school completion and productivity during adulthood [20]. Studies from developing countries, such as Vietnam [21], Indonesia [22] and Guatemala [23], have reported similar results.

Studies conducted in Malaysia support the relationship between SES, nutritional status and cognitive performance. Parental education, household income, birth weight, micronutrient deficiencies and intestinal parasitic infections have been identified as major risk factors for cognitive performance in Malaysian preschool [24] and primary schoolchildren $[1,7]$. However, such studies were limited to indigenous children or primary school-aged children from particular locations in the country. This present study, therefore, aims to determine the association between SES and nutritional status with cognitive performance in a nationally-representative sample of Malaysian children.

\section{Methods}

\section{Study design}

The present study uses Malaysian data from the South East Asian Nutrition Surveys (SEANUTS), which was conducted among children in four countries, namely Indonesia, Malaysia, Thailand and Vietnam. SEANUTS Malaysia was a nationally-representative cross-sectional study conducted among children aged 6 months to 12 years using stratified sampling in all six regions of Malaysia, namely the Northern, Central, Southern, and East Coast regions of Peninsular Malaysia, as well as Sabah and Sarawak [25]. This analysis included a total of 2406 children aged 5 to 12 years (who had complete data for cognitive assessment), representing an estimated 3.55 million Malaysian children in the same age range. Among these children, 631 (24.3\%) were preschool children aged 5 and 6 years old, while 1775 were primary schoolchildren aged 7 to 12 years old.

This study was conducted according to the guidelines laid down in the Declaration of Helsinki, and all procedures involving human subjects were approved by the Research Ethics Committee of Universiti Kebangsaan Malaysia (Project Code: NN-072-2009). Permission to conduct the study was obtained from the Ministry of Education Malaysia and the relevant State Education Departments. Written informed consent was obtained from the parents or guardians of all participants prior to data collection. Details of the study design and sampling protocol have been described elsewhere [25, 26]. This project was registered in the Dutch Trial Registry as NTR2462.

\section{Socioeconomic status}

Socioeconomic information, such as age, sex, ethnicity, parents' education and monthly household income, was obtained from the parents or guardians using a self-administered questionnaire. Parental education was categorized into: (i) non-schooling and primary school, (ii) secondary school and (iii) tertiary level. Household income in Malaysian Ringgit (MYR) was categorized into four groups, using criteria set forth in the Tenth Malaysia Plan [27]: (i) very low income: below MYR 1500 per month; (ii) low income: between MYR 1500 and MYR 2299 per month; (iii) middle income: between MYR 2300 and MYR 5599 per month and (iv) high income: MYR 5600 or more per month [USD $1=$ MYR 4.1405 (as at 28 September 2018)]. 


\section{Cognitive performance}

Trained research assistants administered age-appropriate, validated psychometric Raven's Progressive Matrices (RPM) to assess the non-verbal intelligence quotient (IQ) of the children. Care was taken to administer the RPM to the children individually in a comfortable room that was well lit and free from noise. For children aged 5 to 11 years, Coloured Progressive Matrices (CPM; Raven) [28] were used and Standard Progressive Matrices (SPM; Raven) [29] were administered to children aged 12 years. The CPM consist of three sets of 12 problems, while the SPM consist of five sets of problems, with each set becoming progressively more difficult. Each correct answer was given a score of 1 , making a total raw score of 36 for CPM and 60 for SPM. The total raw scores were then converted into a standard score based on norm tables, and subsequently categorized into the relevant non-verbal IQ categories: $\geq 120$ (superior); 110-119 (high average); 90109 (average), 80-89 (below average); < 80 (low/borderline) $[28,29]$.

\section{Anthropometric status}

Anthropometric measurements, including body weight and height were measured by trained research assistants. The measurements were taken with the children wearing light clothing and not wearing shoes. Height was measured to the nearest $0.1 \mathrm{~cm}$, with a portable SECA stadiometer Model 213 (SECA, Hamburg, Germany). Body weight was taken to the nearest $0.1 \mathrm{~kg}$ using a SECA digital weighing scale Model 803 (SECA, Hamburg, Germany). Measurements were taken twice and the mean was calculated. Body mass index (BMI) was calculated by dividing the measured weight $(\mathrm{kg})$ by the square of height $\left(\mathrm{m}^{2}\right)$.

Anthropometric status was classified according to the age- and sex-specific WHO [30] growth reference using the WHO AnthroPlus 1.0.3 (World Health Organisation, Geneva, Switzerland). The cut off values for thinness was $\mathrm{BAZ}<-2 \mathrm{SD}$, while overweight and obesity were $>1 \mathrm{SD}$ and $>2 \mathrm{SD}$, respectively. Severe obesity was defined as BAZ > 3SD. The cut off value for stunting was $\mathrm{HAZ}<-2 \mathrm{SD}$ [30].

\section{Data analysis}

Data was analyzed using complex samples technique in SPSS version 20.0 (IBM Corporation, New York, USA), using a sampling weight factor developed based on the Malaysian population census 2010 [31]. Descriptive statistics, including mean, standard error (SE), percentage and $95 \%$ confidence interval $(\mathrm{CI})$, were used to describe sociodemographic characteristics, nutritional status and cognitive levels. Likelihood-ratio tests were used to test the association of socioeconomic and nutritional status with IQ categories. The difference in IQ distribution of children by SES and nutritional status was described by percentages and $95 \%$ confidence interval (CI) estimates.

Independent variables which produce likelihood ratio with $p$-value of 0.2 and below in univariate analyses, or change the odds ratio of the variable of interest by $10 \%$ or more, were included in the multivariate logistic regression model. Complex samples logistic regression analyses were performed to determine the odds ratio (OR) after adjusting for putative confounding variables. The OR represents the probability of getting lower IQ relative to those with high average/superior IQ (reference group).

Two regression models were presented. Model 1 was unadjusted with household income, paternal and maternal education, BAZ categories as the primary independent variables. Model 2 was further adjusted by sex, age, ethnicity and residence as these factors had been previously reported to influence children's cognition [7, 32]. The logistic regression models were also checked for the moderating effect of sex and age group on association with IQ levels. Due to insignificant interaction terms $(p>0.05)$, the regression models were presented without stratification. The significance level was set as $p<0.05$ using two-sided tests for all analysis.

\section{Results}

Table 1 illustrates the sample characteristics according to SES, anthropometric status and non-verbal IQ. Mean age of the children was $9.0 \pm 0.1$ years. Nearly $59.1 \%$ were Malays, followed by Chinese (19.2\%), Other ethnicities $(15.0 \%)$ and Indians (6.7\%). A third of the children were from very low income households (< MYR1500 per month) and less than one fifth belonged to high income households ( $\geq$ MYR5600 per month). About two-thirds of the children had parents who had completed secondary school education (fathers: 64.6\%; mothers: 66.4\%). The proportion of children who were stunted, thin and severely obese were $6.0 \%, 6.9 \%$ and $4.9 \%$, respectively.

Four out of ten children (39.1\%) had average non-verbal IQ. A third of the children (35.0\%) had above average (high average and superior) non-verbal IQ, while an eighth (12.2\%) were categorized as having low or borderline IQ (Table 1). The distribution of the children's non-verbal IQ categories by sociodemographic characteristics and nutritional status is shown in Table 2. A larger proportion of children from families with very low household income had low/borderline IQ (17.3\%), while high income households had a larger proportion of children with superior IQ (29.4\%). The same is true for parental education level, where a higher proportion of children whose parents had the lowest education level were categorized as having low/borderline non-verbal IQ (paternal: 17.7\%; maternal: 21.8\%), and, in contrast, a higher proportion of children whose parents had tertiary 
Table 1 Sociodemographic characteristics, nutritional status and intelligence quotient (IQ) of children aged 5.0 to 12.9 years

\begin{tabular}{|c|c|c|c|c|}
\hline & Unweighted count (n) & Estimated population & Percentage (\%) & $95 \% \mathrm{Cl}$ \\
\hline All & 2406 & $3,548,653$ & & \\
\hline \multicolumn{5}{|l|}{ Age (years) } \\
\hline \multicolumn{5}{|l|}{ Sex } \\
\hline Boys & 1201 & $1,823,998$ & 51.4 & $48.7,54.0$ \\
\hline Girls & 1205 & $1,724,655$ & 48.6 & $46.0,51.3$ \\
\hline \multicolumn{5}{|l|}{ Age groups } \\
\hline $5.0-6.9$ years & 631 & 865,374 & 24.3 & $22.3,26.6$ \\
\hline $7.0-9.9$ years & 892 & $1,339,714$ & 37.8 & $35.3,40.3$ \\
\hline $10.0-12.9$ years & 883 & $1,343,566$ & 37.9 & $35.2,40.6$ \\
\hline \multicolumn{5}{|l|}{ Residence } \\
\hline Urban & 1440 & $2,833,601$ & 79.9 & $78.0,81.5$ \\
\hline Rural & 966 & 715,052 & 20.1 & $18.5,22.0$ \\
\hline \multicolumn{5}{|l|}{ Income groups } \\
\hline Below MYR1500 & 863 & $1,104,249$ & 31.1 & 28.7, 33.7 \\
\hline MYR1500-MYR2299 & 434 & 707,382 & 19.9 & $17.8,22.2$ \\
\hline MYR2300-MYR5599 & 712 & $1,111,841$ & 31.3 & $29.0,33.8$ \\
\hline MYR5600 and above & 397 & 625,182 & 17.7 & $15.7,19.7$ \\
\hline \multicolumn{5}{|l|}{ Paternal education level } \\
\hline Non-schooling and primary school & 221 & 281,450 & 7.9 & $6.5,9.7$ \\
\hline Secondary school & 1577 & $2,290,524$ & 64.6 & $62.0,67.1$ \\
\hline Tertiary school & 608 & 976,680 & 27.5 & $25.2,29.9$ \\
\hline \multicolumn{5}{|l|}{ Maternal education level } \\
\hline Non-schooling and primary school & 193 & 248,762 & 7.0 & $5.7,8.7$ \\
\hline Secondary school & 1604 & $2,354,731$ & 66.4 & $63.8,68.8$ \\
\hline Tertiary school & 609 & 945,161 & 26.6 & $24.4,29.0$ \\
\hline \multicolumn{5}{|l|}{ Ethnicity } \\
\hline Malay & 1148 & $2,098,763$ & 59.1 & $56.6,61.6$ \\
\hline Chinese & 593 & 682,464 & 19.2 & $17.5,21.1$ \\
\hline Indian & 172 & 236,120 & 6.7 & $5.5,8.0$ \\
\hline Others & 493 & 531,307 & 15.0 & $13.4,16.6$ \\
\hline
\end{tabular}

Anthropometry

Weight (kg)

Height (cm)

Body mass index $(\mathrm{BMI})\left(\mathrm{kg} / \mathrm{m}^{2}\right)$

BMI-for-age Z-score (BAZ)

Height-for-age Z-score (HAZ)

utritional status

$\begin{array}{ll}\text { Thinness } & 161 \\ \text { Normal weight } & 1548 \\ \text { Overweight } & 314 \\ \text { Obese } & 270 \\ \text { Severe obesity } & 113 \\ \text { Stunted } & 158\end{array}$

244,094
$2,245,077$
462,766
423,983
172,734
213,483


Table 1 Sociodemographic characteristics, nutritional status and intelligence quotient (IQ) of children aged 5.0 to 12.9 years (Continued)

\begin{tabular}{|c|c|c|c|c|c|c|}
\hline & Unweighted count (n) & Estimated population & Percentage (\%) & $95 \% \mathrm{Cl}$ & Mean & SE \\
\hline Low/borderline & 324 & 433,580 & 12.2 & $10.6,14.0$ & & \\
\hline Below average & 307 & 485,845 & 13.7 & $11.8,15.8$ & & \\
\hline Average & 913 & $1,388,445$ & 39.1 & $36.6,41.8$ & & \\
\hline High average & 451 & 651,509 & 18.4 & $16.5,20.4$ & & \\
\hline Superior & 411 & 589,275 & 16.6 & $14.8,18.6$ & & \\
\hline
\end{tabular}

IQ categories: $<80$, low/borderline; 80-90, below average; 90-109, average; $110-119$, high average; $\geq 120$, superior Other ethnic groups include Sarawak bumiputra, Sabah bumiputra, and other bumiputra fUSD 1 = MYR 4.1405 (as at 28 September 2018)

education were categorized as having superior non-verbal IQ (paternal: 25.4\%; maternal: 26.2\%). In terms of ethnic groups, Chinese children had the lowest proportion of low/borderline non-verbal IQ (7.5\%) and the highest proportion of superior non-verbal IQ (28.5\%). There was no significant association of BAZ and HAZ with IQ categories.

Table 3 shows that the OR of logistic regression models improved after adjusting for covariates. Children from households with very low income had twice the odds of having poor non-verbal IQ [low/borderline/ below average, $\mathrm{OR}=2.01$, $(95 \% \mathrm{CI} 1.16,3.49)]$, when compared with children from high-income families. The odds of having poor IQ level also doubled among children whose parents did not attend school or who had completed only primary education, compared with children whose parents had completed tertiary education [paternal, OR $=2.38$ (95\%CI 1.22, 4.62); maternal, $\mathrm{OR}=2.64(95 \% \mathrm{CI} 1.32,5.30)]$. Besides, children whose fathers had completed secondary education had 63\% higher risk of having poor non-verbal IQ level [low/ borderline/below average, $\mathrm{OR}=1.63 \quad(95 \% \mathrm{CI} \quad 1.06$, 2.52)]. The odds of children with severe obesity having poor non-verbal IQ were twice as high compared with normal weight children $[\mathrm{OR}=2.28(95 \% \mathrm{CI} 1.23,4.24)]$.

\section{Discussion}

Our results confirm the association between low SES, in particular low household income and parental education, and poorer cognitive functioning in Malaysian children aged 5-12 years. Children with severe obesity had twice the odds of having poorer non-verbal IQ performance compared to their normal weight counterparts. However, being stunted was not associated with cognitive performance of the children.

In line with previous studies, our study shows that children from low household income families [33, 34] and whose parents had low education levels [33, 35] tended to score lower on the Raven's non-verbal IQ test. Household financial constraints had been associated with such conditions as limited access to cognitively stimulating materials and limited preschool experiences for children [36, 37]. Children from low SES families are more likely to have poorer cognitive performance possibly because of their parents' behavior and life decisions. As people may behave differently when they perceive that required resources are scarce [38], it has been suggested that there is a higher likelihood of poor people engaging in less healthy activities, including tobacco use [39] and alcohol consumption [40]. Hence, different priorities when budgeting limited income may have led to parents with less income not providing the necessary stimulation needed for nurturing their children's cognitive functioning.

On the contrary, parents with higher education may be more willing to invest time and money in caring for their children [41]. In addition, parents with higher education usually have higher health literacy and engage in quality interactions more frequently with their children, as compared to parents with lower education. This explanation is in agreement with that from a Spanish study, which suggested that active parental involvement in the parent-child relationship and the parents' willingness to interact with their children are highly dependent on household SES [42]. A major U.S study showed that parental education was linearly associated with children's total brain surface area [43], which is an indicator for intelligence [44]. Apart from psychosocial factors within the family setting, genetic heritage may also be an important contributing factor towards children's cognitive abilities.

The main effect of severe obesity on cognitive performance seems to corroborate the earlier findings of Sandjaja et al. [16], which reported a similar relationship among Southeast Asian children. However, the negative effect of being overweight or obese on cognitive development as reported by Sandjaja et al. [16] was not shown in this study. There are several possible explanations for the link between severe obesity and non-verbal IQ. One possible explanation is related to nutrition, for example, adequate intake of macro- and micro-nutrients, which is key to brain and cognitive growth, particularly during early childhood. Obesity may indicate adequacy of energy-dense foods but not necessarily the sufficiency 
Table 2 Distribution (\%) of children's intelligence quotient (IQ) by sociodemographic characteristics and nutritional status categories

\begin{tabular}{|c|c|c|c|c|c|c|c|c|c|c|c|c|}
\hline & \multicolumn{2}{|c|}{ Low/borderline } & \multicolumn{2}{|c|}{ Below average } & \multicolumn{2}{|c|}{ Average } & \multicolumn{2}{|c|}{ High average } & \multicolumn{2}{|c|}{ Superior } & \multirow{2}{*}{$\begin{array}{l}\text { Likelihood } \\
\text { ratio }\end{array}$} & \multirow[t]{2}{*}{$p$ value } \\
\hline & Mean & $95 \% \mathrm{Cl}$ & Mean & $95 \% \mathrm{Cl}$ & Mean & $95 \% \mathrm{Cl}$ & Mean & $95 \% \mathrm{Cl}$ & Mean & $95 \% \mathrm{Cl}$ & & \\
\hline \multicolumn{13}{|l|}{ Sex } \\
\hline Boys & 10.1 & $8.3,12.2$ & 14.3 & $\begin{array}{l}11.6 \\
17.5\end{array}$ & 38.0 & $\begin{array}{l}34.5 \\
41.7\end{array}$ & 20.7 & $\begin{array}{l}17.9 \\
23.7\end{array}$ & 16.9 & $\begin{array}{l}14.5 \\
19.7\end{array}$ & 18.726 & $p<0.05$ \\
\hline Girls & 14.5 & $\begin{array}{l}11.9 \\
17.6\end{array}$ & 13.1 & $\begin{array}{l}10.6 \\
16.0\end{array}$ & 40.3 & $\begin{array}{l}36.6 \\
44.1\end{array}$ & 15.9 & $\begin{array}{l}13.5 \\
18.6\end{array}$ & 16.3 & $\begin{array}{l}13.6 \\
19.3\end{array}$ & & \\
\hline
\end{tabular}

Age groups

$\begin{array}{lllllllllllll}5.0-6.9 \text { years } & 14.6 & 11.3, & 11.9 & 9.2,15.4 & 36.0 & 31.5, & 19.4 & 15.9, & 18.1 & 14.8, & 37.301 & p<0.01 \\ & & 18.7 & & & & 40.7 & & 23.4 & & 22.0 & \\ \text { 7.0-9.9 years } & 12.4 & 10.1, & 13.5 & 11.0, & 36.2 & 32.3, & 17.6 & 14.8, & 20.2 & 17.1, & \\ & & 15.1 & & 16.5 & & 40.3 & & 20.9 & & 23.8 & \\ 10.0-12.9 \text { years } & 10.5 & 7.9,13.8 & 15.0 & 11.4, & 44.1 & 39.4, & 18.4 & 15.3, & 12.0 & 9.4,15.2 & \end{array}$

Residence

Urban

$\begin{array}{llllllllll}11.9 & 10.0, & 13.1 & 10.9, & 38.8 & 35.8, & 17.9 & 15.8, & 18.2 & 16.0, \\ & 14.1 & & 15.6 & & 42.0 & & 20.3 & & 20.6 \\ 13.3 & 11.0, & 16.2 & 12.9, & 40.3 & 36.0, & 20.0 & 16.5, & 10.2 & 8.2,12.7 \\ & 16.1 & & 20.1 & & 44.7 & & 24.1 & & \end{array}$

Income groups

Below MYR1500

MYR1500-MYR2299

$\begin{array}{llllllllllll}17.3 & 14.0, & 17.5 & 13.6, & 43.2 & 38.4, & 13.9 & 11.2, & 8.2 & 6.2,10.7 & 151.781 & \begin{array}{l}p< \\ 0.001\end{array} \\ & 21.1 & & 22.2 & & 48.1 & & 17.1 & & & & \\ 12.9 & 9.3,17.7 & 13.9 & 10.3, & 37.9 & 32.0, & 21.5 & 17.0, & 13.8 & 10.4, & & \\ & & & 18.5 & & 44.2 & & 26.9 & & 18.1 & & \\ 9.9 & 7.5,13.0 & 10.9 & 8.4,14.1 & 40.9 & 36.5, & 18.7 & 15.6, & 19.6 & 16.3, & \\ & & & & & 45.5 & & 22.3 & & 23.3 & \\ 6.5 & 4.2,10.1 & 11.8 & 7.9,17.3 & 30.2 & 25.0, & 22.1 & 17.3, & 29.4 & 23.9, & \\ & & & & & 35.9 & & 27.6 & & 35.7 & \end{array}$

Paternal education level

\begin{tabular}{|c|c|c|c|c|c|c|c|c|c|c|c|c|}
\hline $\begin{array}{l}\text { Non-schooling and primary } \\
\text { school }\end{array}$ & 17.7 & $\begin{array}{l}11.9, \\
25.6\end{array}$ & 22.4 & $\begin{array}{l}13.3 \\
35.3\end{array}$ & 36.4 & $\begin{array}{l}27.2 \\
46.7\end{array}$ & 14.4 & $9.2,21.7$ & 9.1 & $5.4,15.0$ & 99.370 & $\begin{array}{l}p< \\
0.001\end{array}$ \\
\hline Secondary school & 14.2 & $\begin{array}{l}12.0 \\
16.7\end{array}$ & 13.6 & $\begin{array}{l}11.5 \\
16.0\end{array}$ & 41.0 & $\begin{array}{l}37.7 \\
44.3\end{array}$ & 17.4 & $\begin{array}{l}15.2 \\
19.9\end{array}$ & 13.8 & $\begin{array}{l}11.8, \\
16.0\end{array}$ & & \\
\hline Tertiary school & 6.0 & $4.0,8.7$ & 11.3 & $8.2,15.4$ & 35.6 & $\begin{array}{l}31.1 \\
40.4\end{array}$ & 21.7 & $\begin{array}{l}18.0 \\
25.9\end{array}$ & 25.4 & $\begin{array}{l}21.2 \\
30.1\end{array}$ & & \\
\hline \multicolumn{13}{|l|}{ Maternal education level } \\
\hline $\begin{array}{l}\text { Non-schooling and primary } \\
\text { school }\end{array}$ & 21.8 & $\begin{array}{l}14.4 \\
31.6\end{array}$ & 21.0 & $\begin{array}{l}12.3 \\
33.4\end{array}$ & 37.9 & $\begin{array}{l}27.7 \\
49.1\end{array}$ & 10.1 & $6.0,16.5$ & 9.3 & 4.9. 17.1 & 119.384 & $\begin{array}{l}p< \\
0.001\end{array}$ \\
\hline Secondary school & 13.5 & $\begin{array}{l}11.5 \\
15.9\end{array}$ & 13.7 & $\begin{array}{l}11.5 \\
16.2\end{array}$ & 42.2 & $\begin{array}{l}39.0 \\
45.5\end{array}$ & 17.1 & $\begin{array}{l}14.9 \\
19.5\end{array}$ & 13.5 & $\begin{array}{l}11.6, \\
15.7\end{array}$ & & \\
\hline Tertiary school & 6.4 & $4.5,9.0$ & 11.9 & $8.7,15.9$ & 31.7 & $\begin{array}{l}27.3 \\
36.5\end{array}$ & 23.8 & $\begin{array}{l}19.9 \\
28.2\end{array}$ & 26.2 & $\begin{array}{l}22.0 \\
30.9\end{array}$ & & \\
\hline \multicolumn{13}{|l|}{ Ethnicity } \\
\hline Malay & 13.5 & $\begin{array}{l}11.2 \\
16.2\end{array}$ & 16.1 & $\begin{array}{l}13.3 \\
19.3\end{array}$ & 41.7 & $\begin{array}{l}38.0 \\
45.5\end{array}$ & 15.5 & $\begin{array}{l}13.0 \\
18.3\end{array}$ & 13.2 & $\begin{array}{l}10.9 \\
16.0\end{array}$ & 117.651 & $\begin{array}{l}p< \\
0.001\end{array}$ \\
\hline Chinese & 7.5 & $5.4,10.2$ & 8.2 & $6.0,11.1$ & 30.5 & $\begin{array}{l}26.3 \\
35.1\end{array}$ & 25.3 & $\begin{array}{l}21.3 \\
29.8\end{array}$ & 28.5 & $\begin{array}{l}24.2 \\
33.2\end{array}$ & & \\
\hline Indian & 17.6 & $\begin{array}{l}12.1 \\
24.9\end{array}$ & 12.0 & $7.4,19.0$ & 45.2 & $\begin{array}{l}35.5 \\
55.3\end{array}$ & 13.0 & $8.3,19.7$ & 12.1 & $6.8,20.8$ & & \\
\hline Others & 10.9 & $7.3,16.0$ & 12.0 & $8.5,16.6$ & 37.3 & $\begin{array}{l}32.2 \\
42.7\end{array}$ & 23.2 & $\begin{array}{l}19.2 \\
27.7\end{array}$ & 16.6 & $\begin{array}{l}13.1 \\
20.8\end{array}$ & & \\
\hline
\end{tabular}

BAZ groups

Thinness 
Table 2 Distribution (\%) of children's intelligence quotient (IQ) by sociodemographic characteristics and nutritional status categories (Continued)

\begin{tabular}{|c|c|c|c|c|c|c|c|c|c|c|c|c|}
\hline & \multicolumn{2}{|c|}{ Low/borderline } & \multicolumn{2}{|c|}{ Below average } & \multicolumn{2}{|c|}{ Average } & \multicolumn{2}{|c|}{ High average } & \multicolumn{2}{|c|}{ Superior } & \multirow{2}{*}{$\begin{array}{l}\text { Likelihood } \\
\text { ratio }\end{array}$} & \multirow[t]{2}{*}{$p$ value } \\
\hline & Mean & $95 \% \mathrm{Cl}$ & Mean & $95 \% \mathrm{Cl}$ & Mean & $95 \% \mathrm{Cl}$ & Mean & $95 \% \mathrm{Cl}$ & Mean & $95 \% \mathrm{Cl}$ & & \\
\hline & & & & 26.9 & & 56.1 & & 24.4 & & & & 0.102 \\
\hline Normal weight & 12.5 & $\begin{array}{l}10.6 \\
14.7\end{array}$ & 11.5 & $9.6,13.8$ & 39.3 & $\begin{array}{l}36.2 \\
42.6\end{array}$ & 18.7 & $\begin{array}{l}16.4 \\
21.3\end{array}$ & 17.9 & $\begin{array}{l}15.7 \\
20.4\end{array}$ & & \\
\hline Overweight & 14.9 & $\begin{array}{l}10.6 \\
20.7\end{array}$ & 14.7 & $9.1,23.0$ & 38.2 & $\begin{array}{l}31.3, \\
45.5\end{array}$ & 19.3 & $\begin{array}{l}14.5 \\
25.2\end{array}$ & 12.9 & $8.9,18.4$ & & \\
\hline Obese & 9.4 & $4.7,17.6$ & 19.4 & $\begin{array}{l}13.0 \\
28.0\end{array}$ & 37.5 & $\begin{array}{l}30.1 \\
45.5\end{array}$ & 19.9 & $\begin{array}{l}14.5 \\
26.6\end{array}$ & 13.9 & $8.5,21.8$ & & \\
\hline Severe obesity & 17.1 & $9.9,28.0$ & 19.0 & $\begin{array}{l}11.4 \\
29.9\end{array}$ & 35.1 & $\begin{array}{l}25.4 \\
46.2\end{array}$ & 10.1 & $5.6,17.5$ & 18.7 & $\begin{array}{l}11.9 \\
28.3\end{array}$ & & \\
\hline \multicolumn{13}{|l|}{ HAZ groups } \\
\hline Stunted & 16.4 & $9.9,26.2$ & 14.8 & $9.0,23.4$ & 36.6 & $\begin{array}{l}26.4 \\
48.2\end{array}$ & 19.4 & $\begin{array}{l}12.3, \\
29.1\end{array}$ & 12.8 & $7.7,20.4$ & 3.969 & $\begin{array}{l}p= \\
0.656\end{array}$ \\
\hline Normal height & 11.9 & $\begin{array}{l}10.3 \\
13.8\end{array}$ & 13.6 & $\begin{array}{l}11.7 \\
15.8\end{array}$ & 39.3 & $\begin{array}{l}36.6 \\
42.0\end{array}$ & 18.3 & $\begin{array}{l}16.4 \\
20.4\end{array}$ & 16.8 & $\begin{array}{l}15.0 \\
18.9\end{array}$ & & \\
\hline
\end{tabular}

IQ categories: < 80, low/borderline; 80-90, below average; 90-109, average; 110-119, high average; $\geq 120$, superior

Other ethnic groups include Sarawak bumiputra, Sabah bumiputra, and other bumiputra

fUSD 1 = MYR 4.1405 (as at 28 September 2018)

of such micronutrients as iron, iodine, zinc and vitamin B12 which have crucial roles in neuropsychological development for cognitive performance [45]. Therefore, it is important that children consume adequate but not excessive macronutrients and sufficient micronutrients, as these nutrients are essential for cognitive development [15]. Furthermore, children with severe obesity may intensify the adverse effect of adiposity [46]. Higher adipose tissues can result in higher adipokines production, including leptin [47]. Adipokine increases insulin resistance and therefore promotes hyperinsulinemia, dyslipidemia, inflammation and endothelial dysfunction [48]. Hypertriglyceridemia (one of the dyslipidemias) will result in elevated peripheral leptin levels, which prevent the entry of leptin to the brain, thus harming brain development $[48,49]$, and consequently lowers cognitive performance.

The finding that severe obesity is associated with low cognitive performance can also be explained by the tendency of severely obese children to have low physical activity levels [50], possibly due to more physical and social barriers to engage in physical activity, compared to their normal weight peers [51]. The lack of physical activity has been associated with poorer cognitive performance, including executive control, working memory and cognitive flexibility in children [52]. Lack of social environment support may also discourage participation in physical activity among children who are obese [53], thus leading to poorer cognitive development.

Notably, our study does not find any association between stunting and cognitive performance. This is in contrast to previous studies which had found that stunted children had lower cognitive performance [18, 54].
However, it is possible that the potential adverse effects of stunting may have been attenuated by high quality home learning environments $[6,21]$. An early childhood study in Vietnam found that the cognitive development disadvantages associated with stunting were found among children whose home learning environments were of low quality, but was absent among children that have good home learning environment [21]. This is supported by a Jamaican study, which reported that stunted children who received home stimulation treatment had significantly superior and longer lasting benefits on cognition compared with those who were only provided with nutrition supplements [6]. Hence, our finding implies that in order to tackle the issues related to cognitive development of children in Malaysia, more attention should be focussed on towards improving not only nutrition but also the factors related to developing stimulating home and learning environment.

The strength of the present study is that by employing a nationally representative sample of Malaysian children in this analysis, we are able to provide, for the first time, insights into the cognitive performance of Malaysian children aged 5 to 12 years and its related factors. However, the generalisability of these results is subject to several limitations. First, due to the cross-sectional design of the study, it is not possible to infer causal relationship between SES or nutritional status with cognitive function. Second, the assessment of cognitive performance was restricted to only non-verbal IQ using RPM, which measures the logical reasoning part of intelligence. Future studies should also include assessment of other components of intelligence that are more representative of basic adaptive skills in social settings, 
Table 3 Odds ratio for intelligence quotient (IQ) by sociodemographic characteristics and nutritional status

\begin{tabular}{|c|c|c|c|c|c|}
\hline \multirow{3}{*}{ Income groups $^{\mathrm{b}}$} & & \multicolumn{2}{|c|}{ Unadjusted model $^{a}$} & \multicolumn{2}{|c|}{ Adjusted model ${ }^{a}$} \\
\hline & & \multirow[t]{2}{*}{$\overline{\mathrm{OR}}$} & \multirow[t]{2}{*}{$95 \% \mathrm{Cl}$} & \multirow[t]{2}{*}{$\mathrm{OR}$} & \multirow[t]{2}{*}{$95 \% \mathrm{Cl}$} \\
\hline & & & & & \\
\hline \multirow[t]{3}{*}{ Below MYR1500 } & Low/borderline/below average & $2.51^{*}$ & $1.47,4.27$ & $2.01^{*}$ & $1.16,3.49$ \\
\hline & Average & $2.27^{*}$ & $1.45,3.54$ & $1.95^{*}$ & $1.24,3.06$ \\
\hline & High average/superior & 1 & & 1 & \\
\hline \multirow[t]{3}{*}{ MYR1500-MYR2299 } & Low/borderline/below average & 1.34 & $0.78,2.30$ & 1.15 & $0.66,2.01$ \\
\hline & Average & 1.30 & $0.82,2.07$ & 1.18 & $0.74,1.90$ \\
\hline & High average/superior & 1 & & 1 & \\
\hline \multirow[t]{3}{*}{ MYR2300-MYR5599 } & Low/borderline/below average & 1.14 & $0.71,1.84$ & 1.06 & $0.65,1.72$ \\
\hline & Average & 1.44 & $0.99,2.09$ & 1.38 & $0.95,2.02$ \\
\hline & High average/superior & 1 & & 1 & \\
\hline \multicolumn{6}{|l|}{ Paternal education level ${ }^{c}$} \\
\hline \multirow[t]{3}{*}{ Non-schooling and primary school } & Low/borderline/below average & 1.78 & $0.93,3.43$ & $2.38^{*}$ & $1.22,4.62$ \\
\hline & Average & 0.90 & $0.51,1.60$ & 1.11 & $0.63,1.97$ \\
\hline & High average/superior & 1 & & 1 & \\
\hline \multirow[t]{3}{*}{ Secondary school } & Low/borderline/below average & 1.42 & $0.93,2.17$ & $1.63^{*}$ & $1.06,2.52$ \\
\hline & Average & 1.01 & $0.73,1.40$ & 1.12 & $0.80,1.55$ \\
\hline & High average/superior & 1 & & 1 & \\
\hline \multicolumn{6}{|l|}{ Maternal education level ${ }^{c}$} \\
\hline \multirow[t]{3}{*}{ Non-schooling and primary school } & Low/borderline/below average & $2.50^{*}$ & $1.25,5.00$ & $2.64^{*}$ & $1.32,5.30$ \\
\hline & Average & $2.07^{*}$ & $1.07,4.02$ & $2.12^{*}$ & $1.10,4.08$ \\
\hline & High average/superior & 1 & & 1 & \\
\hline \multirow[t]{3}{*}{ Secondary school } & Low/borderline/below average & 1.41 & $0.95,2.10$ & 1.34 & $0.89,2.02$ \\
\hline & Average & $1.63^{*}$ & $1.17,2.28$ & $1.55^{*}$ & $1.11,2.17$ \\
\hline & High average/superior & 1 & & 1 & \\
\hline \multicolumn{6}{|l|}{ BAZ groups ${ }^{d}$} \\
\hline \multirow[t]{3}{*}{ Thinness } & Low/borderline/below average & 0.94 & $0.54,1.64$ & 0.79 & $0.45,1.41$ \\
\hline & Average & 1.23 & $0.74,2.03$ & 1.05 & $0.64,1.73$ \\
\hline & High average/superior & 1 & & 1 & \\
\hline \multirow[t]{3}{*}{ Overweight } & Low/borderline/below average & 1.44 & $0.92,2.26$ & 1.45 & $0.93,2.27$ \\
\hline & Average & 1.12 & $0.78,1.62$ & 1.08 & $0.74,1.57$ \\
\hline & High average/superior & 1 & & 1 & \\
\hline \multirow[t]{3}{*}{ Obese } & Low/borderline/below average & 1.32 & $0.83,2.10$ & 1.33 & $0.82,2.17$ \\
\hline & Average & 1.09 & $0.74,1.60$ & 1.06 & $0.69,1.61$ \\
\hline & High average/superior & 1 & & 1 & \\
\hline \multirow[t]{3}{*}{ Severe obesity } & Low/borderline/below average & $2.08^{*}$ & $1.14,3.77$ & $2.28^{*}$ & $1.23,4.24$ \\
\hline & Average & 1.21 & $0.70,2.11$ & 1.28 & $0.73,2.24$ \\
\hline & High average/superior & 1 & & 1 & \\
\hline
\end{tabular}

"Significant odds ratio using complex sample logistic regression at $p<0.05$

${ }^{a}$ Reference category of IQ groups is high average/superior. Sex, ethnicity, age and residence areas (rural/urban) were adjusted in the adjusted model

${ }^{\mathrm{b}}$ Reference category of income groups is high income group (MYR5600 and above). FUSD $1=$ MYR 4.1405 (as at 28 September 2018)

${ }^{c}$ Reference category of paternal and maternal education level is tertiary education level

${ }^{\mathrm{d}}$ Reference category of BAZ groups is normal weight 
such as verbal comprehension and social reasoning. Besides, this study focuses only on SES and nutritional status as determinants of cognitive function. Further investigations into contextual variables may be required to account for other psychosocial and environmental factors - access to cognitively stimulating materials, types of preschool experiences and parent-child interactions $[36,37,42]$ - that affect the cognitive performance of children. Examining the cognitive functioning and behavioral patterns of children from diverse demographic groups may offer further insights into understanding the interplay between the sociodemographic, psychosocial and environmental factors that influence the cognitive performance of children.

\section{Conclusions}

Household income, parental education level and nutritional status are associated with the cognitive performance of 5-to-12 year-old Malaysian children. This study highlights that children from lower socioeconomic classes and those with severe obesity are disadvantaged and are more likely to have poor cognitive performance. The findings of this study indicate the need for further investigation of the interrelated influences between SES and health behaviours, as well as the social and environmental factors that can improve the nutritional status and cognitive health of Malaysian children.

\section{Abbreviations \\ BAZ: BMI-for-age Z-score; BMI: Body Mass Index; Cl: Confidence Interval; CPM: Coloured Progressive Matrices; HAZ: Height-for-age Z-score; IQ: Intelligence Quotient; OR: Odds Ratio; RPM: Raven's Progressive Matrices; SE: Standard Error; SEANUTS: South East Asian Nutrition Surveys; \\ SES: Socioeconomic Status; SPM: Standard Progressive Matrices}

\section{Acknowledgements}

The authors thank all the children and their parents, principals, teachers, and schools for their cooperation. The efforts and dedication of all the researchers, data collection team, enumerators and all those involved in the SEANUTS Malaysia project are much appreciated.

The SEANUTS Study Group comprises the following. Malaysia: Poh Bee Koon, Norimah A Karim, Ruzita A Talib, Siti Balkis Budin, Alvin Ng Lai Oon, Siti Haslinda Mohd Din, Wong Jyh Eiin, Mohd Ismail Noor, Rahman Jamal, Nor Azmi Kamaruddin, Nik Shanita Safii, Chin Yit Siew, Wee Bee Suan, Nor Aini Jamil A. Wahab. FrieslandCampina: Ilse Khouw, Panam Parikh, Swee Ai Ng, Anne Schaafsma, Marjolijn Bragt.

\section{Funding}

This study was funded by FrieslandCampina (Project Codes: NN-072-2009 and NN-2013-112). FrieslandCampina was not involved in the recruitment of participants and the final set of results.

\section{Availability of data and materials}

The datasets used and/or analysed during the current study are available from the corresponding author on reasonable request.

\section{About this supplement}

This article has been published as part of BMC Public Health Volume 19 Supplement 4, 2019: Health and Nutritional Issues Among Low Income Population in Malaysia. The full contents of the supplement are available online at https://bmcpublichealth.biomedcentral.com/articles/supplements/ volume-19-supplement-4.

\section{Authors' contributions}

BKP conceptualized the paper, participated in its design and the writing of the manuscript. STL analyzed data and helped in drafting the manuscript. GSY, KCT, ARNA and ASH wrote the first draft of the paper. PP, JEW and ALON oversaw statistical analysis and revised the manuscript. All authors read and approved the final manuscript.

\section{Ethics approval and consent to participate}

This study was conducted according to the guidelines laid down in the Declaration of Helsinki and all procedures involving human subjects/patients were approved by the Research Ethics Committee of Universiti Kebangsaan Malaysia (Project Code: NN-072-2009). Written informed consent was obtained from the parents or guardians for all children. This project was registered in the Dutch Trial Registry as NTR2462.

\section{Consent for publication}

Not applicable.

\section{Competing interests}

The authors declare that they have no competing interests. Any opinions, findings, conclusions or recommendations expressed in this publication are those of the authors and do not necessarily reflect the views of FrieslandCampina.

\section{Publisher's Note}

Springer Nature remains neutral with regard to jurisdictional claims in published maps and institutional affiliations.

\section{Author details}

${ }^{1}$ Nutritional Sciences Programme \& Centre for Community Health, Faculty of Health Sciences, Universiti Kebangsaan Malaysia, Jalan Raja Muda Abdul Aziz, 50300 Kuala Lumpur, Malaysia. ${ }^{2}$ FrieslandCampina, Amersfoort LE 3818, The Netherlands. ${ }^{3}$ Department of Psychology, School of Science and Technology, Sunway University, 47500 Petaling Jaya, Malaysia.

Published: 13 June 2019

References

1. Al-Mekhlafi HM, Mahdy MA, Sallam AA, Ariffin WA, Al-Mekhlafi AM, Amran $A A$, et al. Nutritional and socio-economic determinants of cognitive function and educational achievement of aboriginal schoolchildren in rural Malaysia. Br J Nutr. 2011;106(7):1100-6.

2. Emerson E, Hatton C. Contribution of socioeconomic position to health inequalities of British children and adolescents with intellectual disabilities. Am J Ment Retard. 2007;112(2):140-50.

3. Bellanti CJ, Bierman KL. Disentangling the impact of low cognitive ability and inattention on social behavior and peer relationships. J Clin Child Adolesc Psychol. 2000;29(1):66-75.

4. Calvin CM, Deary IJ, Fenton C, Roberts BA, Der G, Leckenby N, et al. Intelligence in youth and all-cause-mortality: systematic review with metaanalysis. Int J Epidemiol. 2011;40(3):626-44.

5. Lu C, Black MM, Richter LM. Risk of poor development in young children in low-income and middle-income countries: an estimation and analysis at the global, regional, and country level. Lancet Glob Health. 2016;4(12):e916-22.

6. Walker SP, Wachs TD, Grantham-McGregor S, Black MM, Nelson CA, Huffman SL, et al. Inequality in early childhood: risk and protective factors for early child development. Lancet. 2011;378(9799):1325-38.

7. Hamid Jan JM, Amal KM, Hasmiza H, Pim CD, Ng LO, Wan WM. Effect of gender and nutritional status on academic achievement and cognitive function among primary school children in a rural district in Malaysia. Malays J Nutr. 2011;17(2):189-200.

8. Crosnoe R, Leventhal T, Wirth RJ, Pierce KM, Pianta RC. Family socioeconomic status and consistent environmental stimulation in early childhood. Child Dev. 2010;81(3):972-87.

9. Lorntz B, Soares AM, Moore SR, Pinkerton R, Gansneder B, Bovbjerg VE, et al, Early childhood diarrhea predicts impaired school performance. Pediatr Infect Dis J. 2006;25(6):513-20.

10. Niehaus MD, Moore SR, Patrick PD, Derr LL, Lorntz B, Lima AA, et al. Early childhood diarrhea is associated with diminished cognitive function 4 to 7 years later in children in a northeast Brazilian shantytown. Am J Trop Med Hyg. 2002;66(5):590-3. 
11. Roberts JE, Burchinal MR, Zeisel SA. Otitis media in early childhood in relation to children's school-age language and academic skills. Pediatrics. 2002;110(4):696-706.

12. Bradley RH, Corwyn RF. Socioeconomic status and child development. Annu Rev Psychol. 2002;53(1):371-99.

13. Kamiya Y. Socioeconomic determinants of nutritional status of children in Lao PDR: effects of household and community factors. J Health Popul Nutr. 2011;29(4):339.

14. Babar NF, Muzaffar R, Khan MA, Imdad S. Impact of socioeconomic factors on nutritional status in primary school children. J Ayub Med Coll Abbottabad. 2010;22(4):15-8.

15. Benton D. The influence of dietary status on the cognitive performance of children. Mol Nutr Food Res. 2010;54(4):457-70.

16. Sandjaja S, Poh BK, Rojroonwasinkul N, Le Nyugen BK, Budiman B, Ng LO, et al. Relationship between anthropometric indicators and cognitive performance in Southeast Asian school-aged children. Br J Nutr. 2013; 110(S3):S57-64.

17. Li Y, Dai Q, Jackson JC, Zhang J. Overweight is associated with decreased cognitive functioning among school-age children and adolescents. Obesity. 2008;16(8):1809-15.

18. Warsito O, Khomsan A, Hernawati N, Anwar F. Relationship between nutritional status, psychosocial stimulation, and cognitive development in preschool children in Indonesia. Nutr Res Pract. 2012;6(5):451-7.

19. Hizni A, Julia M, Gamayanti IL. Stunted status and its relationship with the development children aged under five in the north coastal region of Lemahwungkuk District, Cirebon. Indonesia J Clin Nutr. 2009;6:131-7.

20. Sudfeld CR, McCoy DC, Danaei G, Fink G, Ezzati M, Andrews KG, Fawzi WW. Linear growth and child development in low-and middle-income countries: a meta-analysis. Pediatrics. 2015. https://doi.org/10.1542/peds.2014-3111.

21. Nguyen PH, DiGirolamo AM, Gonzalez-Casanova I, Young M, Kim N, Nguyen $S$, et al. Influences of early child nutritional status and home learning environment on child development in Vietnam. Maternal Child Nutr. 2018; 14(1):e12468.

22. Webb KE, Horton NJ, Katz DL. Parental IQ and cognitive development of malnourished Indonesian children. Eur J Clin Nutr. 2005;59(4):618.

23. Johnston FE, Low SM, de Baessa Y, MacVean RB. Interaction of nutritional and socioeconomic status as determinants of cognitive development in disadvantaged urban Guatemalan children. Am J Phys Anthropol. 1987; 73(4):501-6

24. Nasir MT, Norimah AK, Hazizi AS, Nurliyana AR, Loh SH, Suraya I. Child feeding practices, food habits, anthropometric indicators and cognitive performance among preschoolers in Peninsular Malaysia. Appetite. 2012; 58(2):525-30.

25. Poh BK, Ng BK, Haslinda MD, Shanita SN, Wong JE, Budin SB, et al. Nutritional status and dietary intakes of children aged 6 months to 12 years: findings of the nutrition survey of Malaysian children (SEANUTS Malaysia). $\mathrm{Br}$ J Nutr. 2013;110(S3):S21-35.

26. Schaafsma A, Deurenberg P, Calame W, Van Den Heuvel EG, Van Beusekom C, et al. Design of the South East Asian Nutrition Survey (SEANUTS): a fourcountry multistage cluster design study. Br J Nutr. 2013;110(S3):S2-10.

27. DOS. Household income survey report, Department of Statistic, Malaysia. In: Press statement of sistem maklumat kemiskinan negara (E-Kasih). Putrajaya: Implementation Coordination Unit, Prime Minister's Department, Malaysia; 2007.

28. Raven J. Manual coloured progressive matrices and Crichton vocabulary scale. Minnesota: NCS Pearson, Inc; 2008.

29. Raven J. Manual standard progressive matrices- plus Version and Mill Hill vocabulary scale. Minnesota: NCS Pearson, Inc; 2008.

30. World Health Organization. Growth chart for children 5-19 years. 2007 http://www.who.int/growthref/en/. Accessed 22 August 2018.

31. Department of Statistics Malaysia. Population, household and living quarters, Malaysia 2010. Putrajaya: Department of Statistics; 2010.

32. Almomani F, Josman N, Al-Momani MO, Malkawi SH, Nazzal M, Almahdawi KA. Factors related to cognitive function among elementary school children. Scand J Ocup Ther. 2014;21(3):191-8.

33. Santos DN, Assis AM, Bastos AC, Santos LM, Santos CA, Strina A, et al. Determinants of cognitive function in childhood: a cohort study in a middle income context. BMC Public Health. 2008;8(1):202.

34. Schoon I, Jones E, Cheng H, Maughan B. Family hardship, family instability, and cognitive development. J Epidemiol Community Health. 2011. https:// doi.org/10.1136/jech.2010.121228.
35. Bosch SO, Duch $\mathrm{H}$. The role of cognitive stimulation at home in low-income preschoolers' nutrition, physical activity and body mass index. BMC Pediatr. 2017;17(1):178.

36. Bradley RH, Corwyn RF, McAdoo HP, García Coll C. The home environments of children in the United States part I: variations by age, ethnicity, and poverty status. Child Dev. 2001;72(6):1844-67.

37. Piccolo LD, Arteche AX, Fonseca RP, Grassi-Oliveira R, Salles JF. Influence of family socioeconomic status on IQ, language, memory and executive functions of Brazilian children. Psicologia: Reflexão e. Crítica. 2016;29:23.

38. Gennetian LA, Shafir $E$. The persistence of poverty in the context of financial instability: a behavioral perspective. J Policy Anal Manage. 2015;34(4):904-36.

39. Tobacco Control Unit, Cancer Council NSW. The reciprocal relationship between social disadvantage, financial stress and smoking: what does the research tell us? What can community service organisations do? 2008 Smoking and disadvantage seminar, July 23, 2008.

40. Katikireddi SV, Whitley E, Lewsey J, Gray L, Leyland AH. Socioeconomic status as an effect modifier of alcohol consumption and harm: analysis of linked cohort data. Lancet Public Health. 2017;2(6):e267-76.

41. Dotti Sani GM, Treas J. Educational gradients in parents' child-care time across countries, 1965-2012. J Marriage Fam. 2016;78(4):1083-96.

42. Forns J, Julvez J, García-Esteban R, Guxens M, Ferrer M, Grellier J, et al. Maternal intelligence-mental health and child neuropsychological development at age 14 months. Gac Sanit. 2012;26(5):397-404.

43. Noble KG, Houston SM, Brito NH, Bartsch H, Kan E, Kuperman JM, et al. Family income, parental education and brain structure in children and adolescents. Nat Neurosci. 2015:18(5):773.

44. Schnack HG, Van Haren NE, Brouwer RM, Evans A, Durston S, Boomsma DI, et al. Changes in thickness and surface area of the human cortex and their relationship with intelligence. Cereb Cortex. 2014;25(6):1608-17.

45. Black MM. Micronutrient deficiencies and cognitive functioning. J Nutr. 2003:133(11):39275-31S.

46. Pearce $\mathrm{AL}$, Leonhardt CA, Vaidya CJ. Executive and reward-related function in pediatric obesity: a meta-analysis. Child Obes. 2018;10(10):1-15.

47. Tounian P, Aggoun Y, Dubern B, Varille V, Guy-Grand B, Sidi D, et al. Presence of increased stiffness of the common carotid artery and endothelial dysfunction in severely obese children: a prospective study. Lancet. 2001:358(9291):1400-4.

48. Banks WA, Coon AB, Robinson SM, Moinuddin A, Shultz JM, Nakaoke R, et al. Triglycerides induce leptin resistance at the blood-brain barrier. Diabetes. 2004;53(5):1253-60.

49. Dicou E, Attoub S, Gressens P. Neuroprotective effects of leptin in vivo and in vitro. Neuroreport. 2001:12(18):3947-51.

50. Lee ST, Wong JE, Shanita SN, Ismail MN, Deurenberg P, Poh BK. Daily physical activity and screen time, but not other sedentary activities, are associated with measures of obesity during childhood. Int J Environ Res Public Health. 2015;12(1):146-61.

51. Karnik S, Kanekar A. Childhood obesity: a global public health crisis. Int $J$ Prev Med. 2012;3(1):1-7.

52. Syväoja HJ, Tammelin TH, Ahonen T, Kankaanpää A, Kantomaa MT. The associations of objectively measured physical activity and sedentary time with cognitive functions in school-aged children. PLoS One. 2014;9(7): e103559.

53. Franzini L, Elliott MN, Cuccaro P, Schuster M, Gilliland MJ, Grunbaum JA, et al. Influences of physical and social neighborhood environments on children's physical activity and obesity. Am J Public Health. 2009:99(2):271-8.

54. Muhoozi GK, Atukunda P, Diep LM, Mwadime R, Kaaya AN, Skaare AB, et al. Nutrition, hygiene, and stimulation education to improve growth, cognitive, language, and motor development among infants in Uganda: a clusterrandomized trial. Matern Child Nutr. 2018;14(2):e12527. 